\title{
Editorial
}

\section{Saúde Coletiva e Circulação dos Saberes}

| Kenneth R. de Camargo Jr. |

Saber e práticas são indivisivelmente interligados, ainda que não completamente determinados; o fato de existir um corpo formalizado de saberes ligados à intervenção à saúde, como a biomedicina, não significa que se possam deduzir as intervenções a partir daquele corpo, ou seja, que o conhecimento seja a causa da ação. Mas tampouco se pode dizer que a ação é indiferente ao saber; no mínimo ele informa o agir, dialogando em maior ou menor grau com outros saberes e as contingências locais.

Segue-se que tais saberes têm importância fundamental para a atividade humana, e certamente para as ações de saúde; ações mal informadas mais provavelmente levarão a consequências indesejáveis ou mesmo adversas. A análise da formulação de saberes, "leigos” ou “doutos", e sua circulação têm, portanto, papel importante na inteligibilidade de diversos eventos ligados à Saúde Coletiva, como a formulação de demandas por parte da população, a elaboração de políticas públicas e mesmo a própria pesquisa, uma vez que o saber estabelecido também contingencia as possibilidades de emergência do novo.

No tema desta edição de Physis, também elaborado a partir da demanda espontânea de artigos, temos quatro artigos que analisam, sob diversos ângulos, a circulação de determinados saberes, quer na chamada imprensa leiga, quer em periódicos científicos, ou ainda nas novas arenas de comunicação abertas na trilha da internet.

Abrindo o tema, Malinverni e colaboradores analisaram as notícias sobre a ocorrência de casos de febre amarela na passagem de 2007 para 2008, publicadas em um jornal de grande circulação, mostrando as consequências da forma como as dimensões da sua propagação foram exagerados, impactando tanto sobre a política de imunização quanto na exposição de pessoas a riscos desnecessários. Cecchetto e colaboradores analisaram uma publicação 
específica sobre artes marciais, enfocando a questão do uso de anabolizantes como estratégia de aumento rápido de massa muscular entre homens jovens, observando a contradição entre um discurso que condena a prática específica mas aparentemente endossa seus objetivos. Kabad e colaboradores mostram, por meio de revisão sistemática de artigos da base PubMed, como a utilização de conceitos como raça, cor e etnia em estudos epidemiológicos ainda se dá de forma majoritariamente inadequada. Rangel e colaboradores, fechando o tema, apresentam estudo sobre a utilização da internet como ferramenta para fornecer informação adequada sobre nutrição saudável.

Iniciando a seção de temas livres, Brzozowski e Caponi trazem uma reflexão crítica sobre o reducionismo epistemológico de boa parte da literatura recente sobre neurociências, tomando como exemplo a discussão sobre o TDAH. Vannucchi e Carneiro Jr. abordam as vicissitudes da incorporação das ações em saúde mental à atenção primária, com base em estudo empírico. O artigo seguinte, de Athayde e Hennington, de certa forma dialoga com este, ao focalizar, também a partir de um estudo empírico, a saúde dos trabalhadores dos Centros de Atenção Psicossocial (CAPs), afetada pelas dificuldades laborais encontradas naquele cenário.

O artigo de Almeida et al. aborda a imagem corporal no câncer de mama, com base em revisão sistemática de artigos sobre o tema. Bastos e Deslandes interrogam a difícil questão da sexualidade dos portadores de deficiência intelectual, a partir de pesquisa empírica com pacientes de um serviço de referência e seus familiares. Caetano et al. apresentam os resultados de pesquisa com trabalhadores portadores de Distúrbios Osteomusculares Relacionados ao Trabalho (DORT) sobre suas representações sobre o processo saúde-doença.

A pesquisa relatada por Venturiello abordou os itinerários terapêuticos de pessoas com necessidades especiais, mais especificamente com limitações de locomoção, em busca de cuidado e reabilitação na área urbana de Buenos Aires. Van Eyken e Ribeiro fazem em seu artigo uma análise de políticas públicas específicas para a primeira infância no Rio de Janeiro, a partir da ótica do desenvolvimento humano. Gomes e colaboradores relatam estudo sobre a relação médico-paciente no contexto da atenção básica, baseado em entrevistas com médicos e pacientes nesse setting institucional. A elaboração e utilização do prontuário da família é o tema do estudo de Santos e Ferreira, que ressaltam a sua 
relevância, por um lado, e relativo pouco aproveitamento na atenção às famílias.

Fontanela e Gomes fornecem importantes subsídios para a elaboração de estratégias de prevenção do HIV/Aids, analisando os sentidos atribuídos por homens jovens à sexualidade masculina e às suas práticas sexuais. Galvão e Souza exploram as visōes político-pedagógicas expressas pelos gestores de Escolas Técnicas do SUS, nas diferentes regiōes do país. Ruiz e Gerhardt discutem o papel do Estado na formação de uma cidadania solidária e na promoção de saúde a partir de estudos numa comunidade rural do Rio Grande do Sul. Encerrando a seção, Silva e Moraes trazem o resultado da análise da concepção da política de telessaúde em nosso país.

Fechando esta edição, temos as resenhas de Lopes, sobre o livro Avaliação em saúde na perspectiva do usuário: abordagem multicêntrica, organizado por Pinheiro e Martins, e de Kitchenman, sobre Aids e saúde publica: contribuiçôes a reflexão sobre uma nova economia politica dos medicamentos no Brasil, organizado por Correa e Cassier.

\section{ERRATA}

Caros leitores de Physis,

Por motivos alheios a nossa vontade, o último número (v. 22, n. 2) de nossa revista foi impresso com dois pequenos erros: primeiramente, o título correto do tema que deveria constar na capa é Políticas de Saúde e Gestão. Em segundo lugar, o nome completo da quarta autora do artigo "O papel necessário da Agência Nacional de Saúde Suplementar na regulação das relações entre operadoras de planos de saúde e prestadores de serviços" (p. 463-476), é SHEYLA MARIA LEMOS LIMA. 


\section{ERRATA}

\section{Physis-Revista de Saúde Coletiva, v.22, n.3, jul-set 2012}

p. 842, sumário em português, onde se lê “Olga Maria Bastos”, leia-se “Olga Maria Bastos e Suely Ferreira Deslandes”.

p. 846, sumário em inglês, onde se lê “Olga Maria Bastos”, leia-se “Olga Maria Bastos and Suely Ferreira Deslandes”.

p. 850, onde se lê “Bastos interroga”, leia-se “Bastos e Deslandes interrogam”.

p. 1031 (autoria), onde se lê “Olga Maria Bastos”, leia-se “Olga Maria Bastos e Suely Ferreira Deslandes".

p.1045, nota de fim número 1, onde se lê "Baseado na tese Entre o desejo e o medo de ver o filho adolescer: narrativas de pais de adolescentes com deficiência mental, defendida no Programa de Pós-Graduação em Saúde da Criança e da Mulher do IF-Fiocruz, em 2005”, leia-se "Baseado na tese Entre o desejo e o medo de ver o filho adolescer: narrativas de pais de adolescentes com deficiência mental, defendida no Programa de Pós-Graduação em Saúde da Criança e da Mulher do IF-Fiocruz, em 2005. As autoras participaram igualmente de todas as etapas da elaboração do artigo”. 